\title{
Self-consistent modelling of the daytime electron density profile in the ionospheric $F$ region
}

\author{
A. Mikhailov*, K. Schlegel \\ Max-Planck-Institut für Aeronomie, Postfach 20, D-37189 Katlenburg-Lindau, Germany \\ Received: 13 June 1996 / Revised: 30 September 1996 / Accepted: 10 October 1996
}

\begin{abstract}
A theoretical self-consistent method for the description of daytime $N_{e}(h)$ profiles in the ionospheric $\mathrm{F}$ region measured by EISCAT is proposed. It is based on the use of a theoretical F-region model and measured electron density, $N_{e}(h)$, electron, $T_{e}(h)$, and ion temperature, $T_{i}(h)$, and field-aligned plasma drift $V_{l}(h)$ profiles. The method describes the observed $N_{e}(h)$ profile with high accuracy for quiet and disturbed conditions. Two versions of the method are considered: in the first the exospheric temperature $T_{\mathrm{ex}}$ is derived from a procedure minimizing $\left[\log \left(N_{e}(h)_{\text {obs }} / N_{e}(h)_{\text {cal }}\right)\right]^{2}$, in the second $T_{\mathrm{ex}}$ is deduced from the ion energy conservation in the $\mathrm{F}$ region. The method allows us to infer from the incoherent-scatter observations: concentrations of atomic oxygen, [O], molecular oxygen, $\left[\mathrm{O}_{2}\right]$, molecular nitrogen, $\left[\mathrm{N}_{2}\right]$, the vertical plasma drift, $W$, the exospheric temperature. $T_{\mathrm{ex}}$, and the shape parameter $S$ in the neutral temperature profile. The ratio $\left(\left[\mathrm{O}^{+}\right] / N_{e}\right)$ calculated by the theoretical model is used to correct $T_{e}(h), T_{i}(h)$ and $N_{e}(h)$ profiles routinely measured with EISCAT which are known to depend strongly on the actual applied ion-composition model. Such a correction is especially important for geomagnetically disturbed periods when the $F$ region is strongly enriched with molecular ions. We conclude that four of the six thermospheric parameters, namely $[\mathrm{O}],\left[\mathrm{N}_{2}\right], W$ and $T_{\mathrm{ex}}$ can be confidently inferred from the EISCAT observations, while the other two derived parameters, $\left[\mathrm{O}_{2}\right]$ and $S$ are less reliable. The method can be used for the analysis of long-term (seasonal, solar cycle) as well as for day-today variations of the thermospheric parameters and the F-region ion composition using daytime incoherentscatter observations.
\end{abstract} *Permanent address: Institute for Applied Geophysics, 129128
Rostokinskaya 9, Moscow, Russia

\section{Introduction}

A theoretical description of the ionospheric electron density and of the neutral atmospheric parameters can be based on two approaches: in large three-dimensional models (e.g. Fuller-Rowell et al., 1987; Roble et al., 1988; Namgaladze et al., 1990) the thermospheric parameters are calculated using the current understanding of the whole complexity of physical processes in the upper atmosphere. Such models can describe the observed global-scale ionospheric features with some success, but they are not well suited for modelling the ionosphere at smaller scales for the given geophysical conditions of a particular day. The second type of theoretical scheme uses empirical models of neutral composition, temperature and circulation as input parameters (e.g. Kirchengast et al., 1992, and references therein). Such widely used global empirical models as MSIS-83,86 (Hedin, 1983, 1987) for neutral composition and temperature, and HWM-90 (Hedin et al., 1991) for neutral winds, supply averaged values of the thermospheric parameters. Although they were shown to be very efficient at mid-latitudes during relatively quiet conditions, they should be handled with care at high latitudes and during disturbed conditions, when thermospheric parameters exhibit strong variations. Neutral composition together with solar EUV radiation and thermospheric winds are crucial for the F2-layer maximum parameters and measured electron density, $N_{e}(h)$, at the heights of the F1-layer. Therefore the use of empirical neutral composition data for $N_{e}(h)$ modelling is a weak point of most theoretical ionospheric models. According to Sojka (1993) only ionospheric 'climate' but not 'weather' can be modelled nowadays with the help of theoretical models.

Neutral composition and temperature on the other hand, as well as vertical plasma drift [the main aeronomic parameters responsible for the $N_{e}(h)$ distribution in the $\mathrm{F}$ region], may be derived from observed 
ionospheric parameters for the conditions in question; these parameters will then describe the observed $N_{e}(h)$ profile with good accuracy. Such an approach, of course, can not be used for the purposes of ionospheric prediction but it may be very useful and efficient for the understanding of the physical processes involved. It is not a new idea to use ionospheric, in particular incoherent-scatter, data, for the extraction of thermospheric parameters. Incoherent-scatter measurements provide excellent material for such estimates and have been widely used for this purpose for years (Salah et al., 1974; Alcaydé et al., 1974; Evans et al., 1979; Alcaydé, 1979; Oliver, 1979, 1980, 1990; Ganguly et al., 1980; Alcaydé and Fontanari, 1982, 1986; Lathuillere et al., 1983; Hagan and Oliver, 1985; Flå et al., 1986; Burnside and Sulzer, 1988; Burnside et al., 1991; Blelly et al., 1992).

The general approach is based on the use of the ion energy conservation in the $\mathrm{F}$ region and provides valuable information on neutral temperature, atomicoxygen concentration and thermospheric winds. This method however is not straight-forward. Experimental values of ion and electron temperature, $T_{i}, T_{e}$, and to a lesser extent $N_{e}$, depend upon accepted models of ion composition. For the evaluation of routine measurements these models are supposed to be constant (at EISCAT, Millstone Hill, for instance) with respect to changing geophysical conditions. This results in systematic errors in the experimental $T_{i}$ and $T_{e}$ values (Lathuillere et al., 1983; Kirkwood et al., 1986; Winser et al., 1990; Glatthor and Hernandez, 1990) which are used for the solution of the energy equation. Furthermore, the energy equation is usually considered for $\mathrm{O}^{+}$ ions in an atmosphere consisting only of atomic oxygen (Alcaydé and Fontanari, 1982), or the complete neutral composition is taken from an empirical model (Alcaydé and Fontanari, 1986; Winser et al., 1988; Glatthor and Hernandez, 1990). But it is well known that the ion composition changes during geomagnetically disturbed periods and strong electric-field events, leading to an enhanced fraction of molecular ions in the $\mathrm{F}$ region (Glatthor and Hernandez, 1990; Häggström and Collis, 1990). Nevertheless this method is widely accepted, and such popular thermospheric models as MSIS, for instance, are based on neutral temperatures derived with the help of this technique.

In our approach we use $N_{e}(h)$ profiles, as the most reliable parameters measured by the incoherent-scatter technique, to deduce thermospheric data. In addition, the traditional approach based on the ion energy conservation will be considered for comparison. The aim of this paper is (i) to analyse observations of $N_{e}(h)$, $T_{e}(h), T_{i}(h)$ and plasma drift velocities, $V_{l}(h)$ obtained with EISCAT; (ii) to estimate neutral composition, neutral temperature and vertical plasma drift, i.e. the main aeronomic parameters responsible for the F-layer formation; and (iii) to demonstrate the efficiency of the proposed self-consistent approach for modelling the observed $N_{e}(h)$ height distribution. Only sunlit periods from April to September are analysed when the F-layer ionization is produced mainly by solar EUV radiation and the main processes are in principle the same as in the mid-latitude $F$ region. As the proposed method of calculating aeronomic parameters is supposed to deal with a stationary F2-layer, only periods of relative stability in $\mathrm{N}_{\mathrm{m}} \mathrm{F} 2$ and $\mathrm{h}_{\mathrm{m}} \mathrm{F} 2$, namely around noon hours, are selected for the analysis. Geomagnetically quiet as well as disturbed days are considered.

\section{Description of the method}

It is well known that the electron density profile contains complete information about the height distribution of the neutral components and the dynamical processes in the thermosphere. Therefore this information may be deduced in principle from the distribution of the ionospheric-plasma parameters. A first attempt to apply the approach considered in this paper to incoherentscatter data was undertaken by Mikhailov and Ostrovski (1982). The method was based on a simplified F2-region model and dealt only with the F2-layer maximum parameters to analyse the annual variations of atomic oxygen at the location of the Millstone Hill incoherent-scatter facility. In this paper we analyse the complete $N_{e}(h)$ profile and use $T_{e}(h), T_{i}(h)$ and $V_{l}(h)$ profiles observed by EISCAT to obtain information on atomic $[\mathrm{O}]$ and molecular $\left[\mathrm{O}_{2}\right]$ oxygen, molecular nitrogen $\left[\mathrm{N}_{2}\right]$, the vertical plasma drift $W$, the exospheric temperature $T_{\mathrm{ex}}$ and the shape parameter $S$ of the neutral temperature (the square brackets denote the concentration). Unlike other, similar methods used for incoherent-scatter data analysis, the present one allows us to obtain the mentioned thermospheric parameters simultaneously in a self-consistent way.

The theoretical model of the mid-latitude F2 region used in this method takes into account transport processes for $\mathrm{O}^{+}\left({ }^{4} \mathrm{~S}\right)$ and photochemical processes for $\mathrm{O}^{+}\left({ }^{2} \mathrm{D}\right), \mathrm{O}^{+}\left({ }^{2} \mathrm{P}\right), \mathrm{O}_{2}^{+}\left(\mathrm{X}^{2} \Pi\right), \mathrm{N}_{2}^{+}, \mathrm{N}^{+}$and $\mathrm{NO}^{+}$ions in the $120-620-\mathrm{km}$ height range. Table 1 gives the ionneutral and ion-recombination reactions included in the model. Reaction rates are taken from McEwan and Phillips (1975), Oppenheimer et al. (1977), Torr and Torr (1979) and Buonsanto et al. (1992c). The reaction rates 19 and 23 are chosen according to Mikhailov et al. (1989). Atomic-nitrogen concentrations necessary for some reactions are taken from the empirical model MSIS-86. A two-component model of solar EUV from Nusinov (1992) is used to calculate the photoionization rates in 35-wavelength intervals $(10-105 \mathrm{~nm})$. The photoionization and photoabsorption cross-sections are obtained mostly from Torr et al. (1979), but a special analysis was undertaken to account for $\mathrm{O}^{+}\left({ }^{4} \mathrm{~S}\right)$, $\mathrm{O}^{+}\left({ }^{2} \mathrm{P}\right)$ and $\mathrm{O}^{+}\left({ }^{2} \mathrm{D}\right)$ photoionization rates. The chosen scheme of chemical processes was tested using AE-C data on ion composition (Mikhailov et al., 1989) and demonstrated advantages over the most well known ionospheric chemical models. The discussed model was also applied in an analysis of the ion composition measured on board the 'ACTIVNY' satellite (Förster et al., 1995). The standard diffusion equation for a multicomponent ionospheric plasma (Banks and Kock- 
Table 1. chemical reactions included in the self-consistent model.

$T_{\text {eff }}=\left(m_{i} T_{n}+m_{n} T_{i}\right) /\left(m_{i}+m_{n}\right)+0.329 E^{2}$, where $E$ is the electric field perpendicular to the geomagnetic field in $\mathrm{mV} / \mathrm{m}$

\begin{tabular}{|c|c|c|}
\hline Reaction & Rate coefficient & No \\
\hline $\mathrm{O}^{+}\left({ }^{4} \mathrm{~S}\right)+\mathrm{N}_{2} \rightarrow \mathrm{NO}^{+}+\mathrm{N}$ & $\begin{array}{l}1.2 * 10^{-12}\left(300 / T_{\text {eff }}\right), T_{\text {eff }}<740 \mathrm{~K} \\
8.0 * 10^{-14}\left(300 / T_{\text {eff }}\right)^{-2}, T_{\text {eff }}>740 \mathrm{~K}\end{array}$ & 1 \\
\hline $\mathrm{O}^{+}\left({ }^{4} \mathrm{~S}\right)+\mathrm{O}_{2} \rightarrow \mathrm{O}_{2}^{+}+\mathrm{O}$ & $1.0 * 10^{-9} / T_{n}^{0.7}$ & 2 \\
\hline $\mathrm{O}^{+}\left({ }^{2} \mathrm{D}\right)+\mathrm{O} \rightarrow \mathrm{O}^{+}\left({ }^{4} \mathrm{~S}\right)+\mathrm{O}$ & $1.0 * 10^{-10^{n}}$ & 3 \\
\hline $\mathrm{O}^{+}\left({ }^{2} \mathrm{D}\right)+\mathrm{N}_{2} \rightarrow \mathrm{N}_{2}^{+}+\mathrm{O}$ & $1.0 * 10^{-9}$ & 4 \\
\hline $\mathrm{O}^{+}\left({ }^{2} \mathrm{D}\right)+\mathrm{O}_{2} \rightarrow \mathrm{O}_{2}^{+}\left(\mathrm{a}^{4} \Pi\right)+\mathrm{O}$ & $8.0 * 10^{-10}$ & 5 \\
\hline $\mathrm{O}^{+}\left({ }^{2} \mathrm{D}\right)+\mathrm{e} \rightarrow \mathrm{O}^{+}\left({ }^{4} \mathrm{~S}\right)+\mathrm{e}$ & $6.6 * 10^{-8}\left(300 / T_{e}\right)^{0.5}$ & 6 \\
\hline $\mathrm{O}^{+}\left({ }^{2} \mathrm{P}\right)+\mathrm{O} \rightarrow \mathrm{O}^{+}\left({ }^{4} \mathrm{~S}\right)+\mathrm{O}$ & $1.8 * 10^{-10}$ & 7 \\
\hline $\mathrm{O}^{+}\left({ }^{2} \mathrm{P}\right)+\mathrm{N}_{2} \rightarrow \mathrm{N}_{2}^{+}+\mathrm{O}$ & $5.0 * 10^{-11}$ & 8 \\
\hline $\mathrm{O}^{+}\left({ }^{2} \mathrm{P}\right)+\mathrm{N}_{2} \rightarrow \mathrm{O}^{+}\left({ }^{4} \mathrm{~S}\right)+\mathrm{N}_{2}$ & $4.0 * 10^{-10}$ & 9 \\
\hline $\mathrm{O}^{+}\left({ }^{2} \mathrm{P}\right)+\mathrm{e} \rightarrow \mathrm{O}^{+}\left({ }^{2} \mathrm{D}\right)+\mathrm{e}^{2}$ & $1.5 * 10^{-7}\left(300 / T_{e}\right)^{0.5}$ & 10 \\
\hline $\mathrm{O}^{+}\left({ }^{2} \mathrm{P}\right)+\mathrm{e} \rightarrow \mathrm{O}^{+}\left({ }^{4} \mathrm{~S}\right)+\mathrm{e}$ & $3.2 * 10^{-8}\left(300 / T_{e}\right)^{0.5}$ & 11 \\
\hline $\mathrm{O}^{+}\left({ }^{2} \mathrm{P}\right) \rightarrow \mathrm{O}^{+}\left({ }^{2} \mathrm{D}\right)+\mathrm{hv}$ & $\mathrm{A}=0.173 \mathrm{~s}^{-1}$ & 12 \\
\hline $\mathrm{O}^{+}\left({ }^{2} \mathrm{P}\right) \rightarrow \mathrm{O}^{+}\left({ }^{4} \mathrm{~S}\right)+\mathrm{hv}$ & $\mathrm{A}=0.048 \mathrm{~s}^{-1}$ & 13 \\
\hline $\mathrm{O}_{2}^{+}\left(\mathrm{X}^{2} \Pi\right)+\mathrm{N} \rightarrow \mathrm{NO}^{+}+\mathrm{O}$ & $1.8 * 10^{-10}$ & 14 \\
\hline $\mathrm{O}_{2}^{+}\left(\mathrm{X}^{2} \Pi\right)+\mathrm{N} \rightarrow \mathrm{N}^{+}+\mathrm{O}_{2}$ & $4.0 * 10^{-10}$ & 15 \\
\hline $\mathrm{O}_{2}^{+}\left(\mathrm{X}^{2} \Pi\right)+\mathrm{NO} \rightarrow \mathrm{NO}^{+}+\mathrm{O}_{2}$ & $4.4 * 10^{-10}$ & 16 \\
\hline $\mathrm{O}_{2}^{+}\left(\mathrm{X}^{2} \Pi\right)+\mathrm{e} \rightarrow \mathrm{O}+\mathrm{O}$ & $\begin{array}{l}7.7 * 10^{-8}\left(1200 / T_{\mathrm{e}}\right)^{0.56}, T_{\mathrm{e}}>1200 \mathrm{~K} \\
1.95 * 10^{-7}\left(300 / T_{\mathrm{e}}\right)^{0.7}, T_{\mathrm{e}}<1200 \mathrm{~K}\end{array}$ & 17 \\
\hline $\mathrm{N}_{2}^{+}+\mathrm{O} \rightarrow \mathrm{O}^{+}\left({ }^{4} \mathrm{~S}\right)+\mathrm{N}_{2}$ & $1.0 * 10^{-11}\left(300 / T_{\mathrm{n}}\right)^{0.23}$ & 18 \\
\hline $\mathrm{N}_{2}^{+}+\mathrm{O} \rightarrow \mathrm{NO}^{+}+\mathrm{N}$ & $1.4 * 10^{-10}\left(300 / T_{\mathrm{n}}\right)^{0.44}(\times 1.3)$ & 19 \\
\hline $\mathrm{N}_{2}^{+}+\mathrm{O}_{2} \rightarrow \mathrm{O}_{2}^{+}+\mathrm{N}_{2}$ & $5.0 * 10^{-11}\left(300 / T_{\mathrm{n}}\right)$ & 20 \\
\hline $\mathrm{N}_{2}^{+}+\mathrm{N} \rightarrow \mathrm{N}^{+}+\mathrm{N}_{2}$ & $1.0 * 10^{-11}$ & 21 \\
\hline $\mathrm{N}_{2}^{+}+\mathrm{e} \rightarrow \mathrm{N}+\mathrm{N}$ & $3.5 * 10^{-7}\left(300 / T_{\mathrm{e}}\right)^{0.5}$ & 22 \\
\hline $\mathrm{NO}^{+}+\mathrm{e} \rightarrow \mathrm{N}+\mathrm{O}$ & $4.5 * 10^{-7}\left(300 / T_{\mathrm{e}}\right)^{0.83}(\times 1.2)$ & 23 \\
\hline
\end{tabular}

arts, 1973) is used for $\mathrm{O}^{+}\left({ }^{4} \mathrm{~S}\right)$ ions. An implicit difference scheme (Samarski, 1973) is applied to solve the set of difference equations. The observed $N_{e}$ is taken as an upper boundary to solve the continuity equation for $\mathrm{O}^{+}\left({ }^{4} \mathrm{~S}\right)$. The MSIS-83 model (Hedin, 1983) provides the neutral densities in the basic version of the model, but $\mathrm{O}$, $\mathrm{O}_{2}, \mathrm{~N}_{2}$ concentrations, the neutral temperature $T_{n}$ and its shape parameter $S$ are then varied in the $N_{e}(h)$ fitting procedure.

Unlike the mid-latitude F-layer, in the auroral zone strong horizontal $\boldsymbol{E} \times \boldsymbol{B}$ drifts of the ions increase the effective temperature for reaction (1) (Table 1). According to Schunk et al. (1975) we accept for the effective temperature

$T_{\text {eff }}=T_{r}+0.329 E^{2}, \quad T_{r}=\frac{m_{i} T_{n}+m_{n} T_{i}}{m_{n}+m_{i}}$,

where $m_{i}$ and $T_{i}$ are mass and temperature of $\mathrm{O}^{+}$ions, $m_{n}$ and $T_{n}$ are mass and temperature of $\mathrm{N}_{2}$, and $E$ is the electric field in $\mathrm{mV} / \mathrm{m}$. We neglect possible effects of vibrationally exited $\mathrm{N}_{2}$ on the reaction (1) rate because its usefulness in F2-region modelling is questionable (Richards et al., 1994a,b).

Nitric oxide $\mathrm{NO}$ is rather important in the $\mathrm{O}_{2}^{+}$and $\mathrm{NO}^{+}$chemistry, but its distribution is not known for the conditions in question. This problem can be resolved by excluding [NO] from the scheme of chemical processes in the following way: it is well known that the $\left[\mathrm{NO}^{+}\right] /\left[\mathrm{O}_{2}^{+}\right]$ ratio provides a powerful tool for the determination of the NO density. Using $R=\left[\mathrm{NO}^{+}\right] /\left[\mathrm{O}_{2}^{+}\right]$we may write the following expression for the $\mathrm{O}_{2}^{+}$concentration:

$$
\left[\mathrm{O}_{2}^{+}\right]=\frac{q\left(\mathrm{O}_{2}^{+}\right)+q\left(\mathrm{NO}^{+}\right)}{N_{e}\left\{\alpha\left(\mathrm{O}_{2}^{+}\right)+R \alpha\left(\mathrm{NO}^{+}\right)\right\}},
$$

where $q\left(\mathrm{O}_{2}^{+}\right)$is the total production rate of $\mathrm{O}_{2}^{+}$ions and $q\left(\mathrm{NO}^{+}\right)$is the total production rate of $\mathrm{NO}^{+}$ions [except for production via reaction (16) in Table 1], $\alpha\left(\mathrm{O}_{2}^{+}\right)$is the total loss rate of $\mathrm{O}_{2}^{+}$ions [excluding the contribution from reaction (16)] and $\alpha\left(\mathrm{NO}^{+}\right)$is the total loss rate of $\mathrm{NO}^{+}$ions. An empirical height regression for the $R$ parameter (see Fig. 4 in Förster et al., 1995) based on the analysis of all available rocket $\left[\mathrm{NO}^{+}\right] /\left[\mathrm{O}_{2}^{+}\right]$measurements and AE-C data is used in the basic version of the model, but for the condition in question the $R(h)$ dependence can be corrected for a better fit of the calculated to the observed $N_{e}(h)$ at heights below $170 \mathrm{~km}$. Observed $T_{e}(h)$ and $T_{i}(h)$ profiles are used in the calculations.

At each step, varying [O] and the linear loss coefficient $\beta=\gamma_{1}\left[\mathbf{N}_{2}\right]+\gamma_{2}\left[\mathbf{O}_{2}\right]$, the model fits calculated $\mathrm{N}_{\mathrm{m}} \mathrm{F} 2$ and $\mathrm{h}_{\mathrm{m}} \mathrm{F} 2$ to observed values. Molecular oxygen $\left[\mathrm{O}_{2}\right]$ is supposed to vary similarly to $\left[\mathrm{N}_{2}\right]$ in the $\mathrm{h}_{\mathrm{m}} \mathrm{F} 2$ and $\mathrm{N}_{\mathrm{m}} \mathrm{F} 2$ fitting procedure, but the $\left[\mathrm{O}_{2}\right]$ profile is shifted as a whole by a factor which is found in the general minimization procedure. The vertical plasma drift $W$ is obtained from the observed $V_{l}(h)$ with the help of the expression

$$
\begin{aligned}
W= & V_{l} \sin I+\frac{k}{m_{i} \sum v_{i j}} \\
& \times\left[T_{i} \frac{\partial \ln N_{i}}{\partial h}+T_{e} \frac{\partial \ln N_{e}}{\partial h}+\frac{\partial\left(T_{e}+T_{i}\right)}{\partial h}+\frac{g m_{i}}{k}\right] \sin ^{2} I,
\end{aligned}
$$


where $I$ is the magnetic field inclination, $m_{i}$ the $\mathrm{O}^{+}$mass and $N_{i}$ the $\mathrm{O}^{+}$concentration. The diffusion collision frequencies $v_{i}$ for $\mathrm{O}^{+}$are related to the momentum transfer collision frequencies $v^{*}$ by the expression (see Eq. 19.13 in Banks and Kockarts, 1973)

$v_{i j}=\frac{m_{j}}{m_{i}+m_{j}} v_{i j}$

where $i$ denotes $\mathrm{O}^{+}$ions and $j$ other neutral or ionized gas species. Collisions of $\mathrm{O}^{+}$with neutral $\mathrm{O}, \mathrm{O}_{2}, \mathrm{~N}_{2}$ and with $\mathrm{NO}^{+}, \mathrm{O}_{2}^{+}, \mathrm{N}_{2}^{+}, \mathrm{N}^{+}$ions are taken into account. All $\mathrm{O}^{+}$collision frequencies have been taken from Banks and Kockarts (1973).

The scatter of the measured $V_{l}$ around the median $V_{l}(h)$ profile increases with height (as the analysis of the observations shows), so the reliability of the calculated median $V_{l}(h)$ decreases at high altitudes. The vertical plasma drift $W$, on the other hand, is mainly controlled by thermospheric winds and electric fields - both are height independent in the topside F2 region. So we suppose $W$ to be constant above the F2-layer maximum.

The temperature and concentrations of neutrals are calculated in a self-consistent way in the $N_{e}(h)$ fitting procedure. So $T_{n},[\mathrm{O}],\left[\mathrm{O}_{2}\right],\left[\mathrm{N}_{2}\right]$ and $W$ are known at each step in order to solve the continuity equation for $\mathrm{O}^{+}$ and the chemical balance equations for the other ions.

Like any inverse problem, the $N_{e}(h)$ fitting procedure exhibits many local minima for DELTA = $\left[\log \left(N_{e}(h)_{\text {obs }} / N_{e}(h)_{\text {cal }}\right)\right]^{2}$ corresponding to pseudo-solutions, and the problem is to find the global minimum among them. The standard multi-regressional methods turn out to be inefficient to minimize DELTA for the problem in question. Therefore a special procedure of running over the set of unknown aeronomic parameters was developed to localize the position of the global minimum. When its approximate position is found, the standard methods can be applied to obtain the final values for the parameters. This is the MODE1 used to calculate the exospheric temperature $T_{\mathrm{ex}}$, the shape parameter $\mathrm{S}$, the $\mathrm{O}, \mathrm{O}_{2}, \mathrm{~N}_{2}$ concentrations, and the vertical plasma drift $W$. Ion composition is available at each step of the model calculation and is used further for the experimental data refinement (to come).

In addition to MODE1, the same EISCAT observations are analysed with the help of MODE2, based on the ion energy conservation in the $\mathrm{F}$ region to find $T_{\mathrm{ex}}$. This is a widely used approach (see references cited in the Introduction). We used concentrations of $\mathrm{O}, \mathrm{O}_{2}, \mathrm{~N}_{2}$ to calculate the ion collision frequencies of $\mathrm{O}^{+}, \mathrm{NO}^{+}$ and $\mathrm{O}_{2}^{+}$. The only difference to previous approaches is that the neutral concentrations are taken in a selfconsistent way rather than from empirical models. Taking into account the molecular ions may be important for disturbed periods when their contribution becomes essential, even at the heights of F2 region. According to Banks and Kockarts (1973) the equation of ion energy conservation may be written as follows:

$L_{e i}+Q_{i n}=0$,

with

$$
\begin{aligned}
L_{e i} & =3 k\left(T_{e}-T_{i}\right) \sum_{i=1}^{3} N_{i} v_{i e}, \\
Q_{i n} & =\sum_{i=1}^{3} \sum_{n=1}^{3} 3 k \frac{m_{i} N_{i} v_{i n}}{m_{i}+m_{n}}\left[\left(T_{n}-T_{i}\right)+\frac{m_{n}}{3 k}\left(\vec{C}_{i}-\vec{C}_{n}\right)^{2}\right],
\end{aligned}
$$

where $\vec{C}_{i}$ and $\vec{C}_{n}$ are the ion and neutral velocity vectors, all the other symbols are standard. The equation is solved in the $250-400-\mathrm{km}$ height range to find the neutral temperature $T_{n}$ at each height step. These $T_{n}$ values are used to calculate $T_{\mathrm{ex}}$ with the help of Bates (1959) expression:

$T_{e x}=\frac{T_{n}-T_{120} \exp \left[-S\left(h-h_{0}\right)\right]}{1-\exp \left[-S\left(h-h_{0}\right)\right]}$,

where $T_{120}$ is the neutral temperature at $h_{0}=120 \mathrm{~km}$ taken from the MSIS- 83 model. The resultant $T_{\text {ex }}$ is the average of all $T_{\mathrm{ex}}$ values obtained in the $250-400-\mathrm{km}$ height range. All neutral and ion concentrations are calculated in a self-consistent way as already described. The frictional term can be considered as negligible, as long as relative drifts of ions with respect to the neutrals are smaller than about $300 \mathrm{~m} / \mathrm{s}$. This gives an error in the $T_{n}$ calculation of less than $60 \mathrm{~K}$ (Alcaydé and Fontanari, 1986). $T_{\text {ex }}$ calculated without taking into account the frictional term may be considered as an upper boundary for $T_{\mathrm{ex}}$. Electromagnetic drifts are usually small for geomagnetically quiet periods and we may therefore consider this $T_{\mathrm{ex}}$ as reliable. The frictional term can be estimated by minimizing DELTA with respect to the relative ion-neutral drift velocities. It is usually negligible for quiet conditions when the $\boldsymbol{E} \times \boldsymbol{B}$ drift is small; for disturbed periods it is taken into account. Such an example for the disturbed day of 5 August 1992 is considered in Sec. 4.

\section{Data reduction}

The EISCAT CP-1 programme provides range profiles of $N_{e}, T_{e}, T_{i}$ and $\mathrm{V}_{l}$ every 5 min with the antenna beam directed along the local geomagnetic field line. They are used to calculate median profiles with standard deviations at each height step over about an hour (1317 values) for the chosen period. These median vertical profiles are then smoothed by a polynomial of up to $5^{\text {th }}$ degree before being used in the model calculations. It was already mentioned that experimental $N_{e}(h), T_{e}(h)$ and $T_{i}(h)$ profiles depend on the ion composition model applied in the fit of the theoretical to the measured autocorrelation function (ACF) during the incoherentscatter data analysis. The uncertainty in the ion composition may lead to considerable uncertainties in the derived $T_{e}(h)$ and $T_{i}(h)$ profiles and to smaller uncertainties in $N_{e}(h)$ (Lathuillere et al., 1983; Kirkwood et al., 1986; Winser et al., 1990; Glatthor and Hernandez, 1990). The effect of varying ion composition is most noticeable during disturbed periods, but an appreciable effect may also take place for quiet periods, just due to regular seasonal variation in the ion composition. 
In order to correct these uncertainties we applied the following procedure: an ACF was calcultated for each height step $h_{n}$ of the median profiles of $T_{e}, T_{i}$ and $N_{e}$, using the standard incoherent-scatter theory and the standard ion composition $\rho^{0}\left(h_{n}\right)=\left[\mathrm{O}^{+}\right] / N_{e}$ as usually applied in the EISCAT data analysis. These ACFs, which can be regarded as averaged 'measured' ACFs, were then fitted to a theoretical ACF assuming an ion composition $\rho^{1}(h)$ obtained from the ionospheric model in a first step. The resulting $N_{e}, T_{e}$ and $T_{i}$ values were then used as input for the model in a new iteration step $(k)$, as shown schematically in Fig. 1. This approach proved to be quite successful, the composition values $\rho_{n}^{k}$ generally converged within the measuring accuracy after $k=2-3$ iteration steps.

Figure 2 shows, as an example of this iterative procedure, the results for a disturbed day (5 August 1992). The term 'EISCAT Model' (upper left-hand panel) refers to the standard ion-composition model used in the routine EISCAT data analysis. The corresponding profiles $N_{e}^{0}(h), T_{e}^{0}(h), T_{i}^{0}(h)$, as well as the composition $\rho^{1}(h)$, which was obtained by the model, are labelled 'non-corrected' (step $k=0$ in Fig. 1). The other curves correspond to the steps $k=1,2,3$. The finally obtained ion composition (upper left-hand panel) differs appreciably from the initial standard EISCAT ion-composition model in the height range below 300 $\mathrm{km}$, and this results in quite different $T_{i}, T_{e}$ and $N_{e}$ height variations below $300 \mathrm{~km}$ (other three panels) compared to the profiles obtained with the standard composition model. Usually there is no need for such

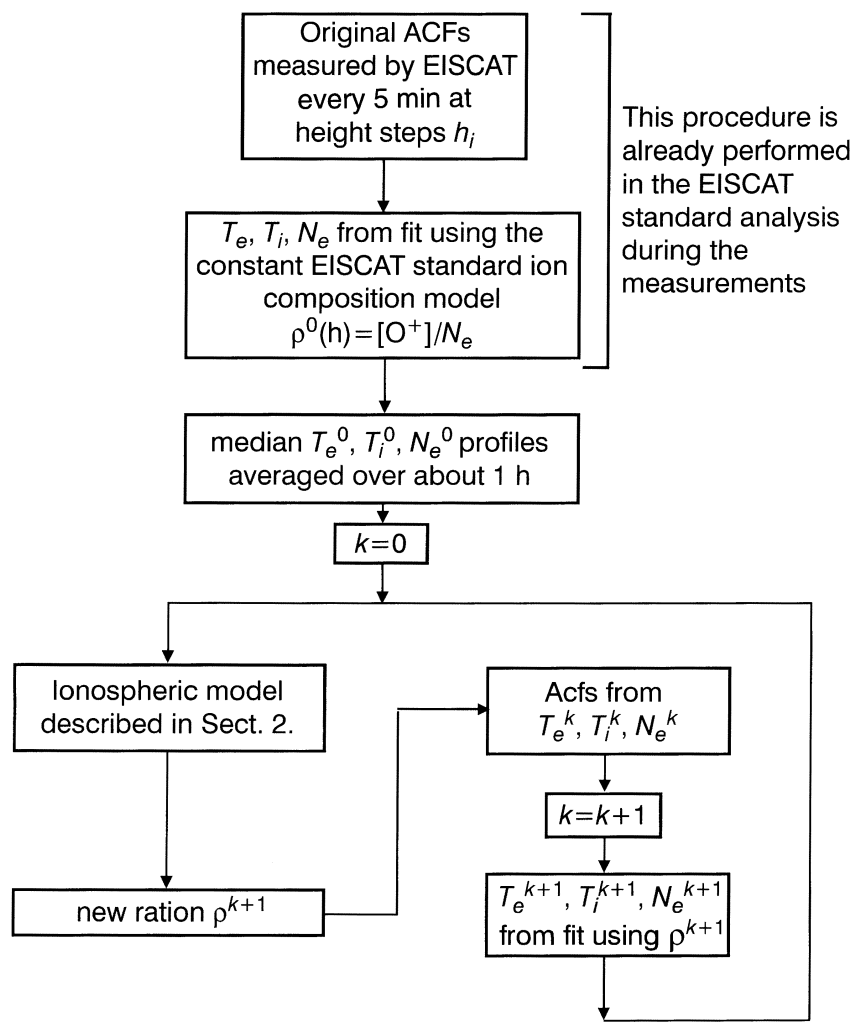

Fig. 1. Explanation of the iteration procedure to correct the measured $T_{e}, T_{i}$ and $N_{e}$ data with respect to the ion composition corrections for quiet periods, as the calculated ioncomposition profile is close to the standard EISCAT model (to be discussed). Four quiet and two disturbed days for the period from April to end of September (Table 2) are analysed with the help of this approach.

The horizontal $\boldsymbol{E} \times \boldsymbol{B}$ ion drifts measured by EISCAT were less than $100 \mathrm{~m} / \mathrm{s}(E<5 \mathrm{mV} / \mathrm{m}$, see Table 2) for quiet days. Strong westward ion drift of about $620 \mathrm{~m} / \mathrm{s}$ $(E \approx 30 \mathrm{mV} / \mathrm{m})$ was observed on 5 August 1992, while on 13 June 1990 the measured drift was small (about $150 \mathrm{~m} /$ s) though it was a very disturbed day with $A_{p}=70$ and $\mathrm{N}_{\mathrm{m}} \mathrm{F} 2$ being 2.3 times smaller in comparison with the previous quiet day, 05 June 1990.

\section{Calculations}

The results of the calculations in comparison with EISCAT $N_{e}(h)$ observations and ion model output are shown in Figs. 3-5. Figure 3 presents the results for two quiet equinoctial days, 2 April 1992 and 25 September 1990. The observed $N_{e}(h)$ profiles are displayed together with \pm standard deviations for the chosen period of observations. The agreement of the calculated and the observed $N_{e}(h)$ profiles is excellent in the whole height range. The calculated height variations for $\left[\mathrm{O}^{+}\right] / N_{e}$ are close to the standard EISCAT ion composition. Therefore no corrections have been necessary for the measured $T_{i}(h), T_{e}(h)$ and $N_{e}(h)$ profiles.

Figure 4 gives an interesting example of two consecutive days, one quiet (4 August 1992 and the other disturbed 5 August 1992). The quiet-time $N_{e}(h)$ profile is quite close to that in Fig. 3. The difference of up to a factor 2.5 between 2 April 1992 and 4 August 1992 in $\mathrm{N}_{\mathrm{m}} \mathrm{F} 2$ is due to seasonal variations in the F2layer maximum parameters and to a lower level of solar activity in August 1992. The disturbed $N_{e}(h)$ profile on 5 August looks quite different with $\mathrm{N}_{\mathrm{m}} \mathrm{F} 2$ decreased by a factor of 2 compared to 4 August and a very pronounced F1-layer maximum around $200 \mathrm{~km}$. Measured $T_{i}(h), T_{e}(h)$ and $N_{e}(h)$ profiles are not corrected for 4 August, although the calculated $\left[\mathrm{O}^{+}\right] / N_{e}$ values are higher than the EISCAT ion model below $200 \mathrm{~km}$. This may be the reason for a small difference between the calculated and the observed electron densities in this height range.

Such a correction of the measured $T_{i}(h), T_{e}(h)$ and $N_{e}(h)$ profiles has been performed for the disturbed day of 5 August 1992 (Fig. 2). The calculated ion composition differs significantly from the standard EISCAT model. A strong enrichment of the ionosphere with molecular ions is seen even at heights of the F2-layer. The corrected $N_{e}(h)$ profile turns out to be even out of the standard deviation band in the $200-250-\mathrm{km}$ range and some difference is seen between the calculated and corrected $N_{i}(h)$ at these altitudes. The rest of the $N_{e}(h)$ profile is described quite well by our calculations. So the correction of the disturbed ion composition for the incoherent-scatter data evaluation seems to be desirable, as the standard EISCAT ion composition is not appropriate in this case. 

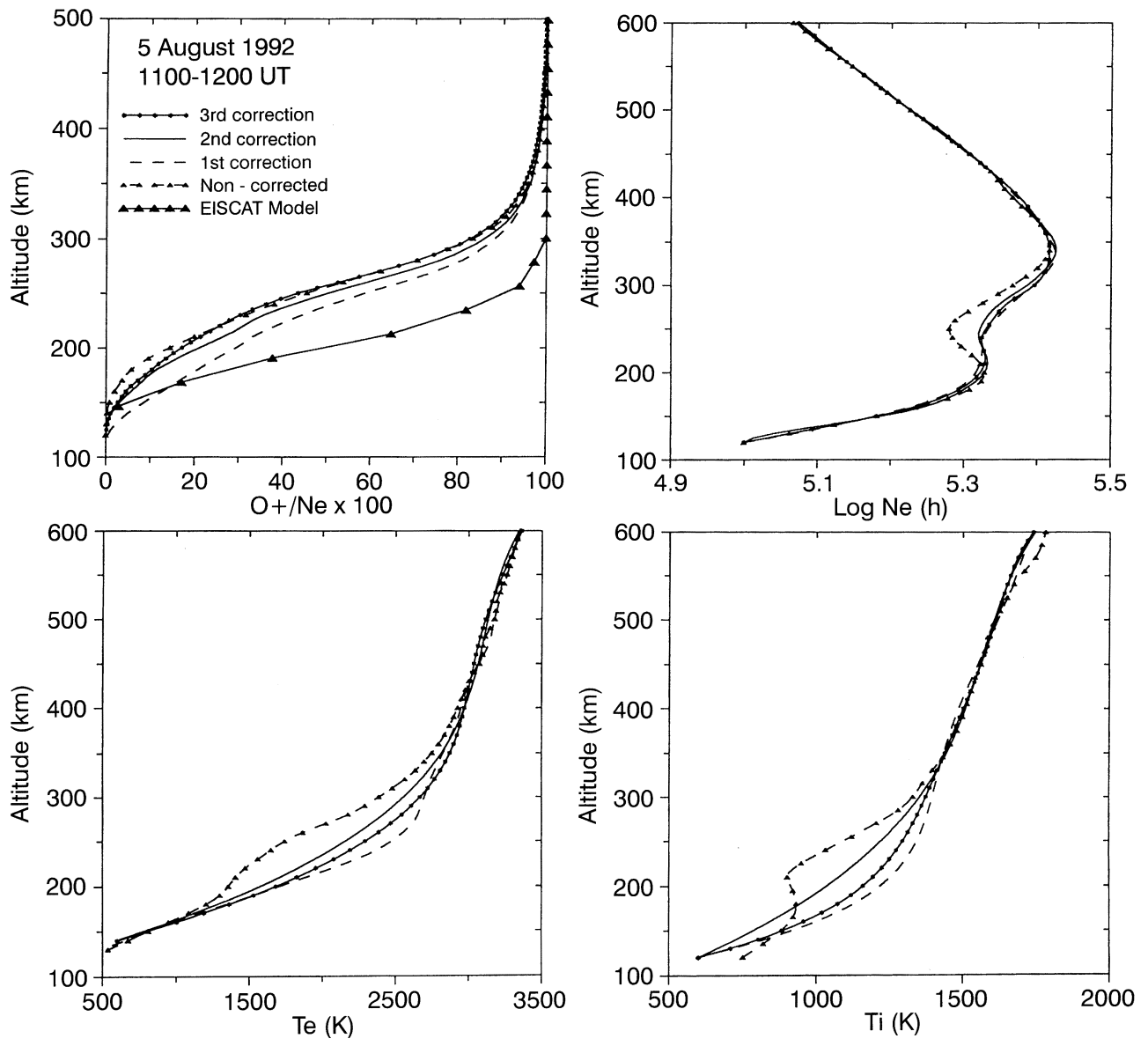

Fig. 2. The EISCAT ion-composition model and three consecutive iterations using the calculated ion composition for the disturbed day of 5 August 1992. Routinely measured ('non-corrected') $N_{e}(h)$, $T_{e}(h)$ and $T_{i}(h)$ profiles are also shown

Figure 5 gives another example of a comparison between a quiet and a disturbed day. The calculations for the quiet day of 5 June 1990 yield a $\left[\mathrm{O}^{+}\right] / N_{e}$ profile close to the EISCAT model, and the observed $N_{e}(h)$ is reproduced with good accuracy in the whole height range. The disturbed day of 13 June 1990 exhibits a decrease in the electron concentration at heights above $160 \mathrm{~km}$ without a pronounced F1 peak but just a ledge around $200 \mathrm{~km}$. This was a very disturbed day with $A_{p}=70$, but unlike the previous case of 5 August 1992, the observed $\boldsymbol{E} \times \boldsymbol{B}$ drifts were small. So we may expect different aeronomic parameters to be responsible for the observed $N_{e}(h)$ variations on these two disturbed days. Similar to the case of 5 August 1992, $k=2-3$ iterations on the ion composition were necessary and again the corrected $N_{e}(h)$ profile remains out of the standard deviation band in the $250-300-\mathrm{km}$ range where the difference between model and calculated ion composition is largest. As in previous cases the overall $N_{e}(h)$ model description of the corrected profile is good.

The results of this comparison show that the accepted set of physical processes and their rates used in our theoretical model allows us to describe the observed daytime $N_{e}(h)$ distribution satisfactorily for various geophysical conditions. The question remains however, whether the deduced aeronomic parameters are reliable.

Let us consider the aeronomic parameters resulting from our self-consistent approach for the dates in question. The results on both, MODE1 and MODE2 calculations in comparison with the MSIS-83 empirical model predictions are given in Table 3.

Some remarks should be made concerning the use of MODE2. The relative drifts of ions with respect to the neutrals are usually small for quiet periods, as was

Table 2. List of the dates used in the study; $\mathrm{FS}_{10.7}$ is a 30-day average of the solar 10.7-cm flux; $E$ is the mean observed electric field during the indicated time-period

\begin{tabular}{lcclcr}
\hline Date & Time (UT) & $A_{P}$ & $\begin{array}{l}\mathrm{F}_{10.7} \\
(\text { day / day-1) }\end{array}$ & $\mathrm{FS}_{10.7}$ & $\begin{array}{l}E \\
(\mathrm{mV} / \mathrm{m})\end{array}$ \\
\hline 2 Apr 1992 & $1220-1320$ & 6 & $161.2 / 186.1$ & 164.5 & $<1.0$ \\
5 Jun 1990 & $1220-1340$ & 5 & $148.3 / 143.9$ & 180.3 & 2.0 \\
13 Jun 1990 & $1220-1340$ & 70 & $202.5 / 215.0$ & 180.3 & $<.0$ \\
4 Aug 1992 & $1130-1230$ & 15 & $130.9 / 131.3$ & 122.1 & $<.0$ \\
5 Aug 1992 & $1100-1200$ & 35 & $130.5 / 130.9$ & 122.1 & 30.0 \\
25 Sep 1990 & $1100-1240$ & 11 & $166.1 / 177.6$ & 194.0 & $<1.0$ \\
\hline
\end{tabular}



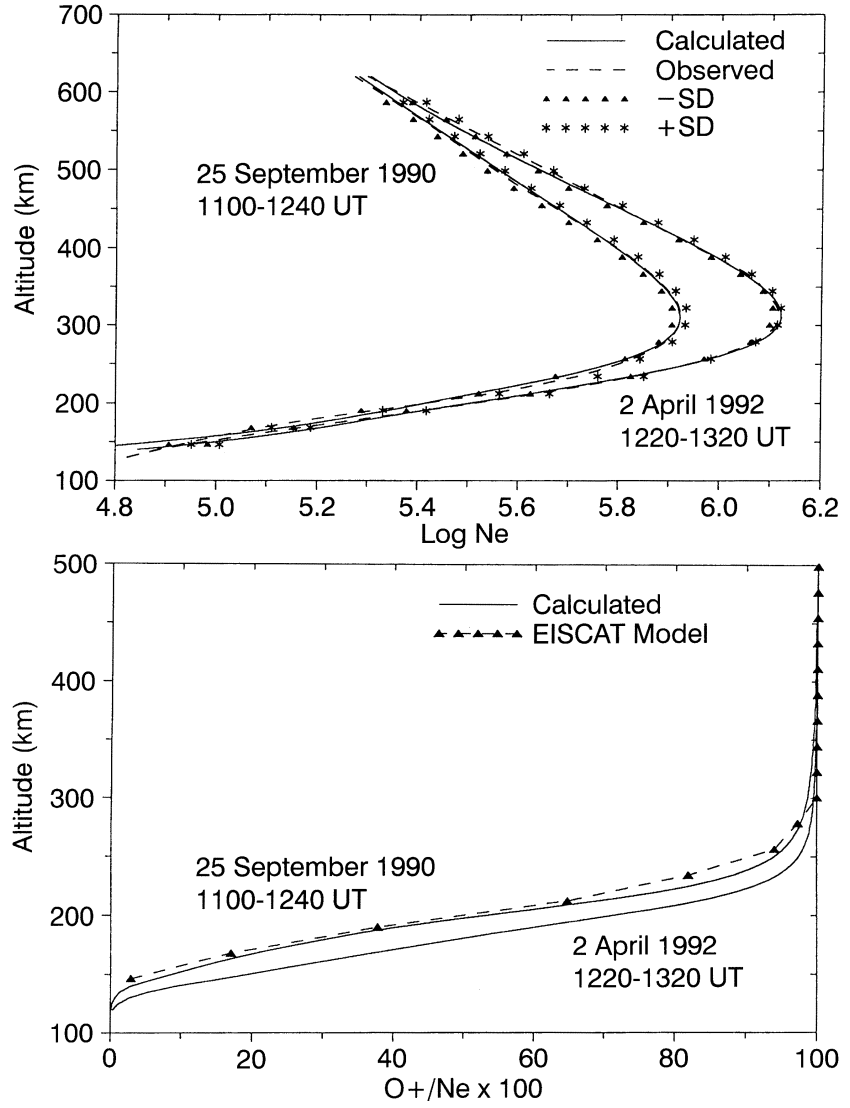

Fig. 3. Observed (together with a band of standard deviations) and calculated $N_{e}(h)$ profiles for two geomagnetically quiet equinoctial days 25 September 1990 and 2 April 1992 (top panel). Calculated and EISCAT model $\left[\mathrm{O}^{+}\right] / N_{e}$ height variations for two days (bottom panel)

already mentioned, therefore the frictional term in Eq. 5 can be considered as negligible. In the case of 5 August 1992 , the observed westward drift was about $620 \mathrm{~m} / \mathrm{s}$ and this can give an appreciable effect in the calculated $T_{\mathrm{ex}}$. As neutral winds are not available for the period in question, we can only estimate the relative drift of ions with respect to the neutrals in Eq. 5 minimizing DELTA in analogy with the procedure applied in MODE1. The results are given in Table 3 , the global minimum in DELTA was found at a relative ion-neutral drift of 650 $\mathrm{m} / \mathrm{s}$. This is a reasonable estimate keeping in mind that the neutral atmosphere may not be dragged by ions (Flå et al., 1986; Glatthor and Hernandez, 1990).

\section{Discussion}

A comparison of the calculated and the observed $N_{e}(h)$ profiles (Figs. 3-5) reveals that daytime EISCAT observations can be theoretically reproduced with high accuracy in the whole range above $150 \mathrm{~km}$ using practically the same scheme of processes commonly applied in mid-latitude F2-layer modelling. This is a confirmation of results obtained by Farmer et al., (1984) in an analysis of EISCAT summertime data, where the authors concluded that the overall behaviour of the Flayer was reminiscent of mid-latitude $\mathrm{N}_{\mathrm{m}} \mathrm{F} 2$ variations.
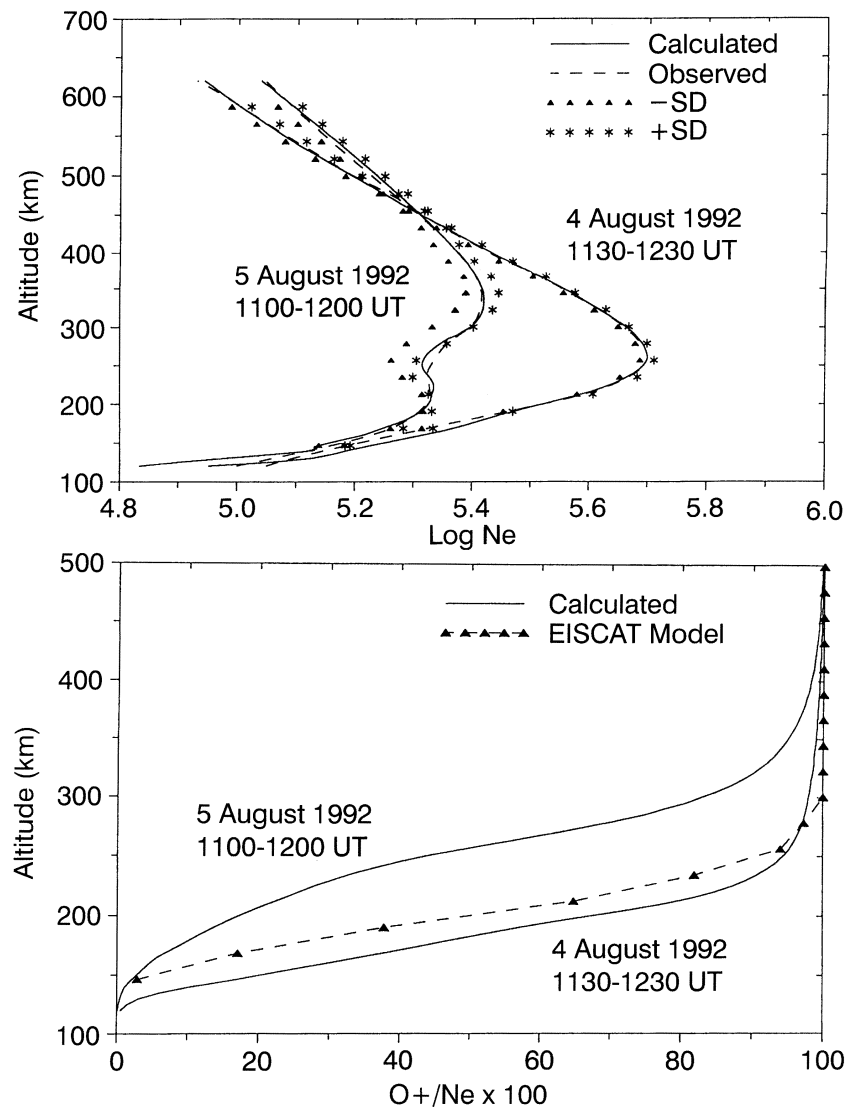

Fig. 4. Same as Fig. 3 but for geomagnetically quiet (5 August 1992) and disturbed (5 August 1992) days

Lathuillere and Brekke (1985), analyzing the ion composition variations, reached the same conclusion they stated: "the F-region ion production at auroral latitudes is mainly controlled by solar radiation, and such auroral phenomena as particle precipitation, enhanced electric fields and Joule heating only introduce second-order effects to the ion composition". This supports our concept that local processes govern the daytime $N_{e}(h)$ distribution in the auroral zone at least for quiet and moderately disturbed conditions analysed in this study.

Let us analyse the calculated aeronomic parameters listed in Table 3. Neutral concentrations are given at the respective F2-layer maximum height rather than at a fixed height, in order to minimize the effect of different neutral temperatures obtained by MODE1 and MODE2, and, for comparison values form MSIS-83. The difference in atomic-oxygen concentration [O] for the two modes is generally below $7 \%$, only in one case on 13 June 1990 is the difference $14 \%$. Similar results apply for $\left[\mathrm{N}_{2}\right]$, the maximal difference is $16 \%$ on 5 June 1990. Both modes give practically the same plasma drift velocities $W$, for both quiet and disturbed days. Typical differences in $T_{\text {ex }}$ are less than $10 \%(120-150 \mathrm{~K})$, except for the disturbed day of 13 June 1990, when MODE2 gives $T_{\mathrm{ex}}=1643 \mathrm{~K}$, which is close to the MSIS- 83 model prediction. This is $300 \mathrm{~K}$ higher than the MODE1 result. The values of $\left[\mathrm{O}_{2}\right]$ look much less satisfactory. There are 

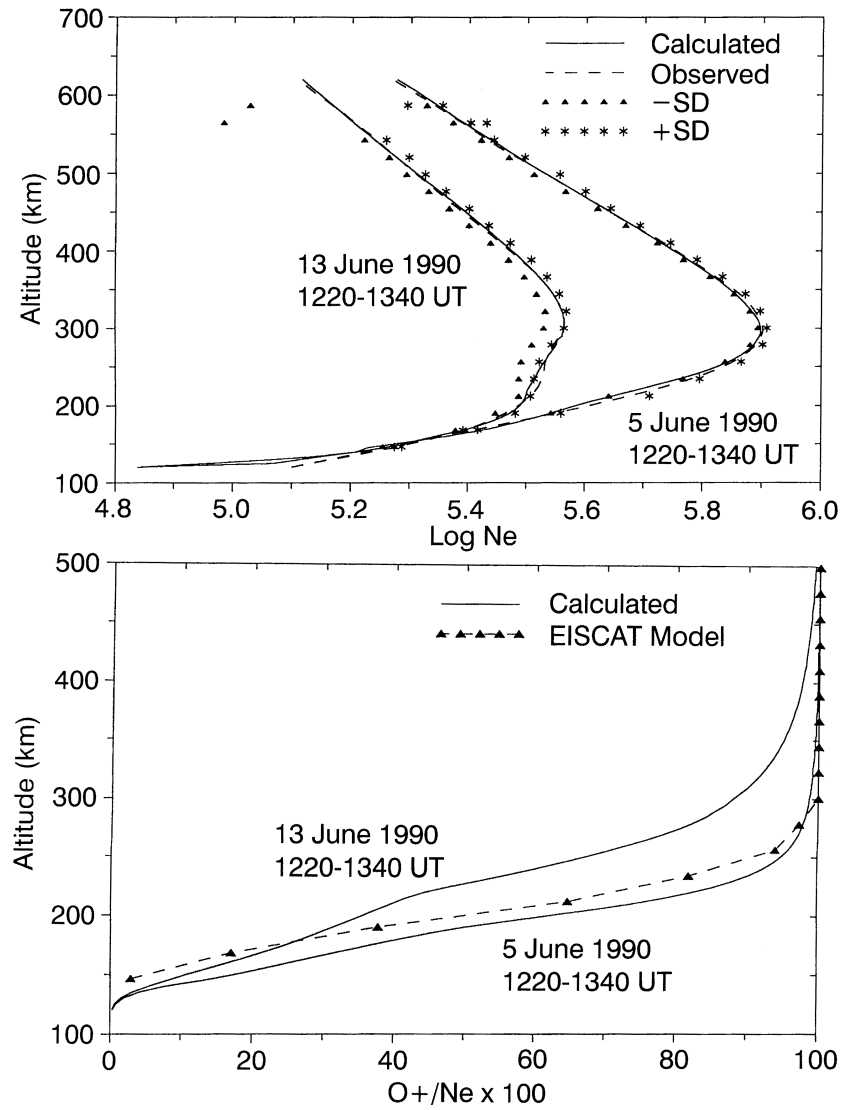

Fig. 5. Same as Fig. 3 but for geomagnetically quiet (5 June 1990) and disturbed (13 June 1990) days

cases when the results of the two modes agree within 10\% (25 September 1990; 4 August 1992; 5 August 1992), but differences of a factor of 2 (5 June 1990) or even 3 (13 June 1990) occur. A comparison of MODE1 with MSIS- 83 gives a typical difference of about $25 \%$ for [O]. This is close to the $30 \%$ difference found by Blelly et al. (1992) in a comparison of calculated values and the CIRA-86 (Hedin, 1988) atomic-oxygen concentration for summer conditions. Similarly, MSIS-83 systematically overestimates $\left[\mathrm{N}_{2}\right]$ by up to $45 \%$. The MSIS- 83 predictions for $T_{\text {ex }}$ are close to the MODE1/MODE2 results - the typical difference is less than $10 \%$. Large differences between the MODE1/MODE2 results and the MSIS-83 predictions occur again for $\left[\mathrm{O}_{2}\right]$, namely factors of 3-5 (5 June 1990; 13 June 1990). The calculated shape parameter $S$ varies in an acceptable range. Only for 5 August 1992 with a value of $0.03 \mathrm{~km}^{-1}$ is $S$ about a factor of 2 higher than the MSIS- 83 predictions. This effect may be attributed to Joule heating resulting from the observed ion drift of $620 \mathrm{~m} / \mathrm{s}$.

The four aeronomic parameters [O], $\left[\mathrm{N}_{2}\right], W$ and $T_{\mathrm{ex}}$ (in MODE1) result mainly from the $\mathrm{N}_{\mathrm{m}} \mathrm{F} 2$ and $\mathrm{h}_{\mathrm{m}} \mathrm{F} 2$ fitting, while $S$ and $\left[\mathrm{O}_{2}\right]$ are more determined by the shape of the $N_{e}(h)$ profile. The F2-layer maximum parameters $\mathrm{N}_{\mathrm{m}} \mathrm{F} 2$ and $\mathrm{h}_{\mathrm{m}} \mathrm{F} 2$ are very reliable since the incoherent-scatter measurements exhibit the highest accuracy in the vicinity of the F2-layer maximum. In addition to $S$ and $\left[\mathrm{O}_{2}\right]$ there are other competing parameters responsible for the $N_{e}(h)$ profile. The plasma temperatures $T_{e}(h)$ and $T_{i}(h)$, for instance, are much more important for the shape of $N_{e}(h)$. Unfortunately the accuracy of the measured $T_{e}$ and $T_{i}$ depends strongly on the accepted ion-composition model, as already mentioned. If the assumed molecular-ion fraction is too large then $T_{e}$ and $T_{i}$ may be underestimated by up to $50 \% ; T_{e}$ and $T_{i}$ may be overestimated by $34 \%$ and $20 \%$, respectively, when the molecular-ion population is entirely neglected (Farmer et al., 1984).

Therefore observed $T_{e}$ and $T_{i}$ values at low altitudes $(<300 \mathrm{~km})$ must be treated with particular caution. Our iteration results on ion composition (Fig. 2) confirm this conclusion. Keeping all this in mind, we can state that the reliability and accuracy of the deduced $S$ and $\left[\mathrm{O}_{2}\right]$ are probably not very high. The parameters $[\mathrm{O}],\left[\mathrm{N}_{2}\right], W$ and $T_{\mathrm{ex}}$, however, can be considered as reliable. A

Table 3. Calculated thermospheric parameters and MSIS- 83 model predictions at the height of $h_{m} F 2$

\begin{tabular}{llllllll}
\hline Date & Mode & $\begin{array}{l}\log [\mathrm{O}] \\
\left(\mathrm{cm}^{-3}\right)\end{array}$ & $\begin{array}{l}\log \left[\mathrm{O}_{2}\right] \\
\left(\mathrm{cm}^{-3}\right)\end{array}$ & $\begin{array}{l}\log \left[\mathrm{N}_{2}\right] \\
\left(\mathrm{cm}^{-3}\right)\end{array}$ & $\begin{array}{l}S \\
\left(\mathrm{~km}^{-1}\right)\end{array}$ & $\begin{array}{l}T_{\text {ex }} \\
(\mathrm{K})\end{array}$ & $\begin{array}{l}W \\
(\mathrm{~m} / \mathrm{s})\end{array}$ \\
\hline $2 \mathrm{Apr} 1992$ & M1 & 8.932 & 6.823 & 8.205 & 0.014 & 1400 & -7.5 \\
$\mathrm{~h}_{\mathrm{m}} \mathrm{F} 2=313 \mathrm{~km}$ & M2 & 8.947 & 6.684 & 8.245 & 0.020 & 1282 & -7.7 \\
& MSIS & 8.828 & 6.952 & 8.332 & 0.019 & 1288 & \\
$25 \mathrm{Sep} 1990$ & M1 & 8.794 & 6.510 & 8.334 & 0.014 & 1335 & -11.3 \\
$\mathrm{~h}_{\mathrm{m}} \mathrm{F} 2=313 \mathrm{~km}$ & M2 & 8.826 & 6.494 & 8.363 & 0.014 & 1393 & -12.9 \\
& MSIS & 8.891 & 7.052 & 8.456 & 0.022 & 1257 & \\
4 Aug 1992 & M1 & 8.907 & 7.495 & 8.676 & 0.020 & 1205 & -13.4 \\
$\mathrm{~h}_{\mathrm{m}} \mathrm{F} 2=261 \mathrm{~km}$ & M2 & 8.910 & 7.497 & 8.678 & 0.021 & 1184 & -13.4 \\
& MSIS & 8.822 & 7.562 & 8.829 & 0.018 & 1201 & \\
$5 \mathrm{Aug} 1992$ & M1 & 8.317 & 6.945 & 8.198 & 0.030 & 1130 & 11.8 \\
$\mathrm{~h}_{\mathrm{m}} \mathrm{F} 2=338 \mathrm{~km}$ & M2 & 8.314 & 6.980 & 8.185 & 0.033 & 1105 & 12.2 \\
& MSIS & 8.273 & 6.699 & 8.032 & 0.017 & 1263 & \\
$5 \mathrm{Jun} 1990$ & M1 & 8.768 & 6.598 & 8.401 & 0.016 & 1240 & -5.9 \\
$\mathrm{~h}_{\mathrm{m}} \mathrm{F} 2=298 \mathrm{~km}$ & M2 & 8.765 & 6.874 & 8.336 & 0.014 & 1395 & -5.5 \\
& MSIS & 8.763 & 7.078 & 8.549 & 0.019 & 1307 & \\
13 Jun 1990 & M1 & 8.592 & 6.816 & 8.631 & 0.019 & 1340 & -16.8 \\
$\mathrm{~h}_{\mathrm{m}} \mathrm{F} 2=308 \mathrm{~km}$ & M2 & 8.659 & 7.335 & 8.615 & 0.012 & 1643 & -18.7 \\
& MSIS & 8.557 & 7.512 & 8.772 & 0.014 & 1687 & \\
\hline
\end{tabular}


systematic difference up to $45 \%$ in $\left[\mathrm{N}_{2}\right]$ with respect to the MSIS-83 model predictions is quite normal for the high-latitude thermosphere. A comparison of $\left[\mathrm{N}_{2}\right]$ measured on board the DE-2 satellite with MSIS-83 predictions gives the ratio $0.5-0.9$ for quiet geomagnetic conditions (Hedin and Carignan, 1985). Similar comparisons for disturbed days reveal that MSIS- 83 exceeds the DE-2 measurements on $\left[\mathrm{N}_{2}\right]$ by 2.5 times at latitudes higher than $70^{\circ}$ (Roble et al., 1987).

An interesting result confirming again the validity of the proposed approach, is a comparison of ion composition. The standard EISCAT ion-composition model represents an average $\left[\mathrm{O}^{+}\right] / N_{e}$ height profile independent of seasonal and geophysical conditions. Our results are close to this profile, but yield an ionosphere with a slightly higher $\mathrm{O}^{+}$abundancy for quiet periods. A similar conclusion was obtained by Shibata et al. (1995) on the $[\mathrm{O}]^{+} / N_{e}$ variations from an EISCAT data analysis for geomagnetically quiet days. Table 5 gives a comparison of our calculated transition $\left([\mathrm{O}]^{+} / N_{e}=0.5\right)$ heights, $z_{50}$, with the statistical model of ion composition by Lathuillere and Pibaret (1992). Our calculated transition heights are close to their model predictions for the quiet days, except for 25 September, but they are much higher for the disturbed days of 13 June and 5 August. The difference for 25 September may be attributed to the poorly represented autumn period (only 3 days) in the statistical model, while the difference for disturbed days needs a special analysis which is beyond the scope of this paper.

On disturbed days, however, the contribution of molecular ions strongly increases even at heights around the F2-layer maximum (Figs. 4,5). A similar enrichment of the $\mathrm{F}$ region with molecular ions at times of strong electric fields was considered by Häggström and Collis (1990). Their electric field for 28 July 1987 was much stronger (up to $90 \mathrm{mV} / \mathrm{m}$ ) compared to $30 \mathrm{mV} / \mathrm{m}$ in our case for 5 August 1992; consequently they observed the dominance of molecular ions up to $400 \mathrm{~km}$, while on 5
August 1992 molecular ions dominate only up to $260 \mathrm{~km}$ (Fig. 4). This effect partly results from the increase in the reaction rate of the ion-molecular reaction $\left(\mathrm{O}^{+}+\mathrm{N}_{2}\right.$, No. 1 in Table 1), as $T_{\text {eff }}$ depends on the square of the electric field. An additional increase in the $\mathrm{O}^{+}$loss rate is due to the overall $\left[\mathrm{N}_{2}\right]$ and $\left[\mathrm{O}_{2}\right]$ increase for disturbed days. These changes are shown in Table 4 , where the aeronomic parameters are given at a fixed height of 300 $\mathrm{km}$ to compare quiet and disturbed days. A decrease in atomic oxygen $[\mathrm{O}]$ and an increase in molecular species $\left[\mathrm{N}_{2}\right]$ and $\left[\mathrm{O}_{2}\right]$ is quite typical for the high-latitude thermosphere during the periods of geomagnetic disturbances. For the 4-5 August case the comparison reveals an increase by a factor of 3.2 in $\left[\mathrm{O}_{2}\right]$, a factor of 2.8 in $\left[\mathrm{N}_{2}\right]$, a factor of 2 in $\gamma_{1}$ and a factor of 5.4 in the overall linear loss rate $\beta$. Similarly, the comparison of 13 June/5 June gives the following variations: 2.2 for $\left[\mathrm{O}_{2}\right]$, 2.1 for $\left[\mathrm{N}_{2}\right], 1.4$ for $\gamma_{1}$ and 3.0 for $\beta$. The essential contribution to the increase in $\beta$ on 5 August 1992 is provided by $\gamma_{1}$, due to its dependence on the electric field, while the $\beta$ variation for 13 June/5 June mainly results from neutral composition changes. Two ionmolecular reactions ( 1 and 2 in Table 1$)$ are the main channels for the conversion of $\left[\mathrm{O}^{+}\right]$to molecular ions. Consequently, the stronger $\beta$ changes, the larger will be the ratio $\left[\mathrm{O}^{+}\right] / N_{e}$ at F-region heights (cf. Figs. 4 and 5).

The importance of the correct ion composition has been stressed by many authors (e.g. Lathuillere et al., 1983; Kirkwood et al., 1986; Winser et al., 1990; Glatthor and Hernandez., 1990), since errors in experimental $T_{e}(h), T_{i}(h)$ and $N_{e}(h)$ distributions may lead to a wrong physical interpretation. The proposed self-consistent approach to the $N_{e}(h)$ modelling can be successfully used for the correction of observed ionospheric parameters when the calculated ion composition turns out to be very different from the model.

The main difference between MODE1 and MODE2 consists in the calculation of the exospheric temperature, as already explained, $T_{\mathrm{ex}}$ derived from the ion energy

Table 4. Calculated aeronomic parameters for quiet (q) and disturbed (d) days at $300 \mathrm{~km}$ altitude

\begin{tabular}{llllllcc}
\hline Date & $\begin{array}{l}\log [\mathrm{O}] \\
\left(\mathrm{cm}^{-3}\right)\end{array}$ & $\begin{array}{l}\log \left[\mathrm{O}_{2}\right] \\
\left(\mathrm{cm}^{-3}\right)\end{array}$ & $\begin{array}{l}\log \left[\mathrm{N}_{2}\right] \\
\left(\mathrm{cm}^{-3}\right)\end{array}$ & $\begin{array}{l}T_{\text {ex }} \\
(\mathrm{K})\end{array}$ & $\begin{array}{l}\gamma_{1} / 10^{-12} \\
\left(\mathrm{~cm}^{3} / \mathrm{s}\right)\end{array}$ & $\begin{array}{l}\gamma_{2} / 10^{-13} \\
\left(\mathrm{~cm}^{3} / \mathrm{s}\right)\end{array}$ \\
\hline 4 Aug 1992 q & 8.631 & 6.970 & 8.215 & 1205 & 1.13 & 3.12 & 1.88 \\
5 Aug 1992 d & 8.585 & 7.473 & 8.660 & 1130 & 2.22 & 2.71 \\
5 Jun 1990 q & 8.768 & 6.598 & 8.401 & 1240 & 1.31 & 1.80 \\
13 Jun 1990 d & 8.653 & 6.932 & 8.733 & 1340 & 1.85 & 2.40 \\
\hline
\end{tabular}

Table 5. Heights, $z_{50}$ of the transition $\left(\left[\mathrm{O}^{+}\right] / N_{e}=0.5\right)$ calculated by our method in comparison with the statistical model of Lathuillere and Pibaret (L-P)

\begin{tabular}{llllll}
\hline Date & $\begin{array}{l}\text { Time } \\
(\mathrm{UT})\end{array}$ & F10.7 & $K p$ & $\begin{array}{l}z_{50}, \text { this method } \\
(\mathrm{km})\end{array}$ & $\begin{array}{l}z_{50}, \text { L-P model } \\
(\mathrm{km})\end{array}$ \\
\hline 2 Apr 1992 & $1220-1320$ & 161.2 & 1.3 & 180 & 188 \\
5 Jun 1990 & $1220-1340$ & 148.3 & 1.7 & 189 & 185 \\
13 Jun 1990 & $1220-1340$ & 202.5 & 6.3 & 227 & 193 \\
4 Aug 1992 & $1130-1230$ & 130.9 & 1.3 & 182 & 185 \\
5 Aug 1992 & $1100-1200$ & 130.5 & 4.0 & 256 & 192 \\
25 Sep 1990 & $1100-1240$ & 166.1 & 1.7 & 199 & 176 \\
\end{tabular}


equation, Eq. 5, corresponds to one of the pseudosolutions and does not provide the best $N_{e}(h)$ fit. Figure 6 illustrates the search for the solution on 5 June 1990 with the help of MODE1. The top panel represents a one-dimensional cut (along the $T_{\mathrm{ex}}$ axis) of the DELTA surface. The global minimum position is clearly seen around $T_{\mathrm{ex}}=1240 \mathrm{~K}$ and the parameters corresponding to this minimum are accepted as the final solution. It should be kept in mind however, that although MODE1 yields $T_{\mathrm{ex}}$ corresponding to the best $N_{e}(h)$ fit, real observed median $N_{e}(h)$ profiles exhibit a scatter resulting in a band of $T_{\mathrm{ex}}$ values. Therefore it does not make much sense to find the exact $T_{\text {ex }}$ value which provides the best fit, and it is better instead to consider a plateau of acceptable solutions. Indeed, the other parameters $\left[\mathrm{O}_{2}\right]$, $\left[\mathrm{N}_{2}\right]$ and $W$ do not vary strongly with $T_{\mathrm{ex}}$ as Fig. 6 shows. So $T_{\mathrm{ex}}$ seems not to be a very crucial parameter for the problem in question. From a practical point of view this result can simplify the search for the solution the MODE2, for instance, is much less computer timeconsuming than MODE1.

A self-consistently derived vertical plasma drift $W$ can be fully related to the meridional thermospheric wind $V_{\mathrm{nx}}$

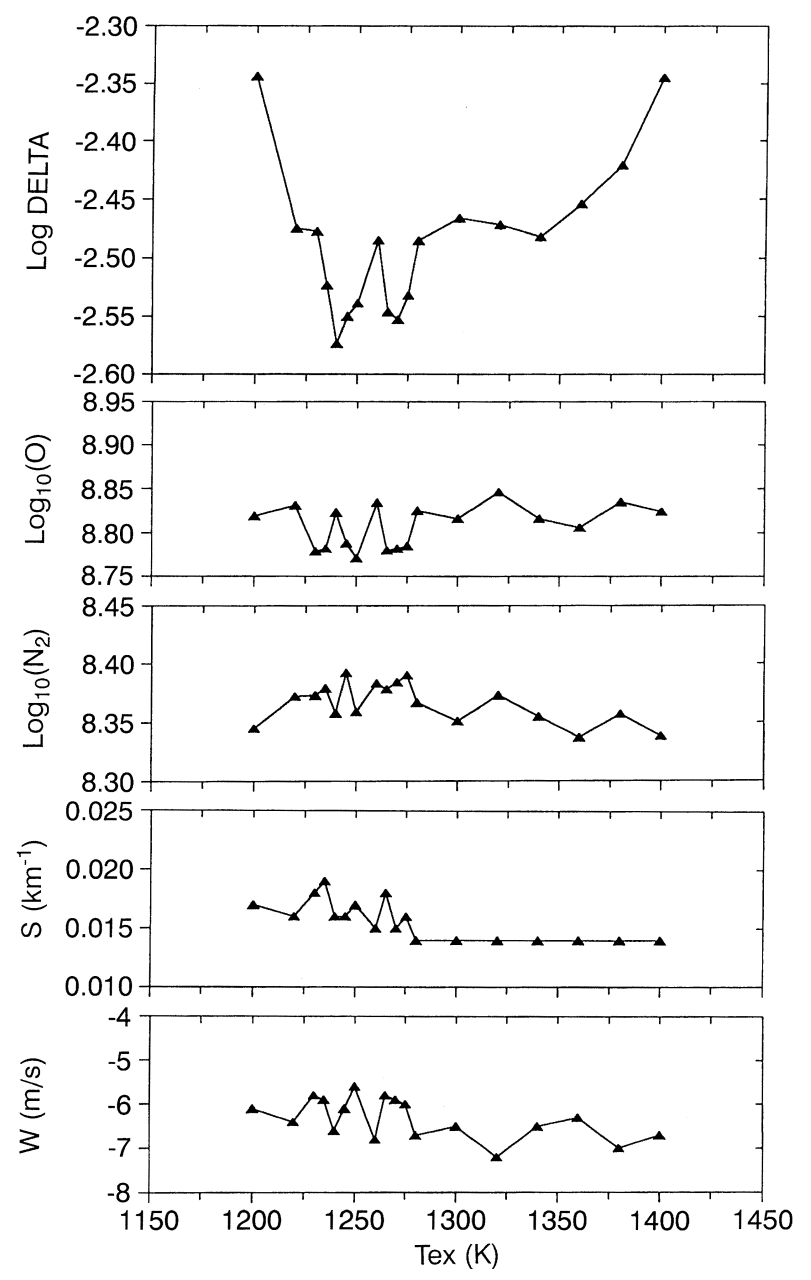

Fig. 6. A one-dimensional cut along the $T_{\text {ex }}$ axis of the DELTA surface to illustrate the search for a DELTA global minimum (top panel) and calculated $\log [\mathrm{O}], \log \left[\mathrm{N}_{2}\right], S$ and $W$ variations in the considered $T_{\mathrm{ex}}$ range; the density units are $\mathrm{cm}^{-3}$
(Farmer et al., 1984). The declination at Tromso is $1.24^{\circ}$, so the zonal wind component is not efficient at least for near-noon hours when $V_{\text {ny }}$ (zonal component) is not large. For all dates except for 5 August 1992 the calculated vertical drifts (Table 3 ) correspond to a 20 $80 \mathrm{~m} / \mathrm{s}$ northward neutral wind. A similar estimate of $V_{\mathrm{nx}}$ of about $80 \mathrm{~m} / \mathrm{s}$ was obtained by Alcaydé et al., (1984) for daytime summer conditions. A strong upward plasma drift of $12 \mathrm{~m} / \mathrm{s}$ at the heights of the F2-layer maximum is obtained only for 5 August 1992 . The most plausible explanation is an upwelling of the neutral atmosphere due to Joule heating, since the $\boldsymbol{E} \times \boldsymbol{B}$ ion drift was about $620 \mathrm{~m} / \mathrm{s}$ for the period in question.

All collison frequencies used in our model are taken from Banks and Kockarts (1973), and $v\left(\mathrm{O}^{+}-\mathrm{O}\right)$ in particular. In recent studies using incoherent-scatter data it was sugested that this collision-frequency value should be increased by a factor of 1.7 (Burnside et al., 1987; Burnside and Sulzer, 1988; Buonsanto et al., $1992 \mathrm{a}, \mathrm{b})$. The possible effect of such a correction is discussed in Blelley et al. (1992). They point out that the inferred oxygen densities would have to be decreased by the same factor and this would contradict the CIRA-86 model. A lower factor of $1.2-1.4$ for the $v\left(\mathrm{O}^{+}-\mathrm{O}\right)$, collision-frequency correction was recently recommended by Pesnell (1993), Reddy et al. (1994) and Davis et al. (1995). This is closer to the value of Banks and Kockarts (1973). According to our calculations there is no need to increase the $v\left(\mathrm{O}^{+}-\mathrm{O}\right)$ value given by these authors, but simultaneous daytime incoherentscatter and satellite measurements of neutral-composition or netural-wind observations are required to finally settle this question.

The accuracy of calculated aeronomic parameters depends on many input quantities and can hardly be estimated strictly. Direct independent and simultaneous satellite observations of neutral composition and temperature could, for instance, be used for such a strict comparison. A comparison with empirical (i.e. averaged) thermospheric models like MSIS-83 can give only a rough estimate, especially in the auroral zone where the thermosphere is extremely variable. A lower boundary of expected errors resulting from the uncertainty in the measured ionospheric parameters can be estimated with the help of expressions relating the daytime F2-layer maximum parameters $\mathrm{N}_{\mathrm{m}} \mathrm{F} 2$ and $\mathrm{h}_{\mathrm{m}} \mathrm{F} 2$ to the aeronomic parameters [O], $\beta$ and $W$ (Ivanov-Kholodny and Mikhailov, 1986, p.45). From those relationships the following expressions may be derived:

$$
\begin{aligned}
\Delta \log [\mathrm{O}]= & 7.5 * 10^{-3} \Delta h_{m}+0.578 \Delta \log N_{m} \\
& -1.68 * 10^{-2} \Delta W \\
\Delta \log \beta= & 1.25 * 10^{-2} \Delta h_{m}-0.578 \Delta \log N_{m} \\
& -1.42 * 10^{-2} \Delta W .
\end{aligned}
$$

The uncertainty in the measured electron concentration is $10-12 \%$ according to Farmer et al., (1984) and Kirkwood et al., (1986) (resulting in an uncertainty in $\Delta \log \mathrm{N}_{m} \mathrm{~F} 2$ of about \pm 0.05 ), while the $\log \mathrm{N}_{\mathrm{m}} \mathrm{F} 2$ scatter around the median value used in our calculations is two 
times smaller. The $h_{m} F 2$ scatter around its median value usually is $\pm 10 \mathrm{~km}$ over the chosen $1-\mathrm{h}$ period of observations. The uncertainty in measured field-aligned plasma velocity is $\pm 2 \mathrm{~m} / \mathrm{s}$ at the height of $300 \mathrm{~km}$ (Jones et al., 1986). This gives an uncertainty of $\approx 16 \%$ in [O] and $\approx 18 \%$ in the linear loss coefficient $\beta$. As $\beta$ is mainly determined by molecular nitrogen this estimate may be also applied to $\left[\mathrm{N}_{2}\right]$. But it should be kept in mind that these estimates are lower boundary errors for the calculated [O] and $\left[\mathrm{N}_{2}\right]$.

The applicability of the method is demonstrated here for near-noon sunlit hours when the F2-layer is controlled by local processes and may be considered as stationary. For such conditions the proposed method can be used for a routine derivation of neutral thermospheric parameters and ion composition at least for geomagnetically quiet and moderately disturbed periods. In principle the method can be extended to other sunlit intervals of the day when the F2-layer is non-stationary.

\section{Conclusions}

The main results of the paper can be summarized as follows:

1. We propose a theoretical self-consistent method for the description of day-time EISCAT $N_{e}(h)$ profiles in the ionospheric $F$ region. Four geomagnetically quiet and two disturbed days were considered for summer and equinoctial periods to demostrate the efficiency of the method. It is based on the use of a F2-region theoretical model together with observed $N_{e}(h), T_{e}(h), T_{i}(h)$ and $V_{l}(h)$ profiles. The method allows us to describe the observed $N_{e}(h)$ distribution above $150 \mathrm{~km}$ for quiet and disturbed conditions with high accuracy. The present approach confirms that a set of main processes commonly accepted for mid-latitudes can be successfully used to model the daytime auroral F2-layer at least for quiet and moderately disturbed conditions.

2. In a self-consistent way the method allows us to derive such important thermospheric parameters as: concentrations of atomic oxygen, [O], molecular oxygen, $\left[\mathrm{O}_{2}\right]$, molecular nitrogen, $\left[\mathrm{N}_{2}\right]$, vertical plasma drift, $W$, exospheric temperature, $T_{\mathrm{ex}}$, and the shape parameter $S$ of the height dependence of the neutral temperature.

3 . The ion composition $\left(\left[\mathrm{O}^{+}\right] / \mathrm{N}_{e}\right.$-ratio) calculated by the theoretical model can be used to correct routinely measured $T_{e}(h), T_{i}(h), N_{e}(h)$ profiles which are known to be strongly dependent on the accepted ion-composition model. Such a correction is especially important for geomagnetically disturbed periods when the $\mathrm{F}$ region is strongly enriched with molecular ions even at the heights of F2-layer maximum.

4. Two versions of the method are developed. In MODE1 the exospheric temperature $T_{\mathrm{ex}}$ is inferred from the minimization of DELTA $=\left[\log \left(N_{e}(h)_{\text {obs }} / N_{e}(h)_{\text {cal }}\right)\right]^{2}$; in MODE2 $T_{\mathrm{ex}}$ is derived from the ion energy conservation in the $\mathrm{F}$ region. The difference in $T_{\mathrm{ex}}$ derived by the two modes does generally not exceed $150 \mathrm{~K}(12 \%)$; only for the disturbed day of 13 June 1990 is the difference up to $300 \mathrm{~K}$. The calculated neutral composition and vertical plasma drift, on the other hand, vary only marginally within this range of the $T_{\mathrm{ex}}$ uncertainty.

5. The comparison between both modes has shown agreement in the calculated [O] and $\left[\mathrm{N}_{2}\right]$, a $17 \%$ difference occurs only in one case (13 June 1990) for [O], and a $16 \%$ difference in $\left[\mathrm{N}_{2}\right]$ on 5 June 1990 . The calculated vertical plasma drifts $W$ agree in both modes, and they yield a reasonable estimate for the meridional neutral thermospheric wind. We conclude that four of six thermospheric parameters, namely [O], [ $\left.\mathrm{N}_{2}\right], W$, and $T_{\text {ex }}$ can be inferred from the $N_{e}(h), T_{e}(h), T_{i}(h)$ and $V_{l}(h)$ EISCAT observations with confidence, while the other two parameters $\left[\mathrm{O}_{2}\right]$ and $S$ are less reliable.

6. The developed technique is applicable to a routine derivation of the neutral thermospheric parameters and the F-region ion composition in the vicinity of an incoherent-scatter facility for near-noon sunlit hours when the F2-layer can be considered as stationary. The method can be used for the analysis of long-term (seasonal, solar cycle) as well as for day-to-day variations of the thermospheric and ionospheric parameters.

Acknowledgements. The authors thank the Director and the staff of EISCAT for running the radar and providing the data. The EISCAT Scientific Association is funded by scientific agencies of Finland (SA), France (CNRS), Germany (MPG), Norway (NF), Sweden (NFR), and the United Kingdom (PPARC). A.M. is grateful to the Max-Planck-Gesellschaft for a research stipend at the MPAE.

Topical Editor D. Alcaydé thanks J. E. Salah and J. Fontanari for their help in evaluating this paper

\section{References}

Alcaydé D., Incoherent scatter data related to thermospheric modelling, Space Res., 19, 211-229, 1979.

Alcaydé, D., and J. Fontanari, High-latitude neutral atmosphere temperature and concentration measurements from the first EISCAT incoherent scatter observation, Ann. Geophys., 38, 473-480, 1982.

Alcaydé, D., and J. Fontanari, Neutral temperature and winds from EISCAT CP-3 observations, J. Atmos. Terr. Phys., 48, 931-947, 1986.

Alcaydé, D., P. Bauer, and J. Fontanari, Long-term variations of thermospheric temperature and composition, J. Geophys. Res., 79, 629-637, 1974

Alcaydé, D., P. Bauer, and J. Fontanari, Dynamic coupling of the auroral F-region ionosphere and thermosphere:case-studies, $J$. Atmos. Terr.Phys., 46, 625-633, 1984.

Banks, P. M., and G. Kockarts, Aeronomy, Academic Press, New York, London, 1973.

Bates, D. R., Some problems concerning the terrestrial atmosphere above $100 \mathrm{~km}$ level. Proc. R. Soc. London, A, 253, 451-462, 1959.

Blelly, P. L., J. Fontanari, D. Alcaydé, J. Wu, M. Blanc, and T. L. Hanse, Observations of the structure and vertical transport of the polar upper ionosphere with the EISCAT-VHF radar. Ann. Geophysicae, 10, 394 406, 1992.

Buonsanto, M. J., J. Foster, and D. P. Sipler, Observations from Millstone Hill during the geomagnetic disturbances of March and April 1990. J. Geophys. Res., 97. 1225-1243, 1992a.

Buonsanto, M. J., Y.-K. Tung, and D. P. Sipler, Neutral atomic oxygen density from radar and optical wind measurements at Millstone Hill. J. Geophys. Res., 97. 8673-8679, 1992 b. 
Buonsanto, M. J., S. C. Solomon, and W. K. Tobiska, Comparison of measured and modeled solar EUV flux and its effect on the E-F1 region ionosphere, J. Geophys. Res., 97, 10513-10524, 1992c.

Burnside, R. G., and M. P. Sulzer, Determination of the thermospheric temperatures and neutral densities at Arecibo from the ion energy balance. J. Geophys. Res., 93, 8642-8650, 1988.

Burnside, R. G., C. A. Tepley, and V. P. Wickwar, The $\mathrm{O}^{+}-\mathrm{O}$ collision cross-section: can it be inferred from aeronomic measurements? Ann. Geophysicae, 5, 343-350, 1987.

Burnside, R. G., C. A. Tepley, and M. P. Sulzer, World day observations at Arecibo: 1985-1989, J. Geophys. Res., 96, 36913710, 1991.

Davis, C. J., A. D. Farmer, and A. Aruliah, An optimized method for calculating the $\mathrm{O}^{+}-\mathrm{O}$ collision parameter from aeronomic measurements, Ann. Geophysicae, 13, 541-550, 1995.

Evans, J. V., W. L. Oliver, Jr., and J. E. Salah, Thermospheric properties as deduced from incoherent scatter measurements, $J$. Atmos, Terr. Phys., 41, 259-278, 1979.

Farmer, A. D., M. Lockwood, R. B. Horne, B. J. I. Bromage, and K. S. C. Freeman, Field-perpendicular and field-aligned plasma flows observed by EISCAT during a prolonged period of northward IMF, J. Atmos, Terr. Phys., 46, 473-488, 1984.

Flå, T., A. Skoelv, U. P. Løvhaug, and A. Brekke, Thermospheric wind measurements with EISCAT, J. Atmos, Terr. Phys., 48, 949-958, 1986.

Förster, M., V. Mikhailov, A. Mikhailov, and J. Smilauer, A theoretical interpretation of ion composition measured on board the 'Activny' satellite in the European sector during April 10-12, 1990 geomagnetic storm. Ann. Geophysicae, 13, 608-616, 1995.

Fuller-Rowell, T. J., D. Rees, S. Quegan, R. J. Moffett, and G. J. Bailey, Interactions between neutral thermospheric composition and the polar ionosphere using a coupled ionosphere-thermosphere model. J. Geophys. Res., 92, 7744-7748, 1987.

Ganguly, S., J. C. G. Walker, and H. Rishbeth, The dynamic F2layer over Arecibo, J. Atmos. Terr. Phys. 42, 553-562, 1980.

Glatthor, N., and R. Hernandez, Temperature anisotrophy of drifting ions in the auroral F-region, observed by EISCAT, $J$. Atmos. Terr. Phys., 52, 545-560, 1990.

Hagan, M. E., and W. L. Oliver, Solar cycle variability of exospheric temperature at Millstone Hill between 1970 and 1980, J. Geophys. Res., 90, 12265-12270, 1985.

Häggström, I., and P. N. Collis, Ion composition changes during Fregion density depletions in the presence of electric fields at auroral latitudes, J. Atmos. Terr. Phys., 52, 519-529, 1990.

Hedin, A. E., A revised thermospheric model based on massspectrometer and incoherent scatter data MSIS-83, J. Geophys. Res., 88, 10170-10188, 1983.

Hedin, A. E., MSIS-86 thermospheric model. J. Geophys. Res., 92 , 4649-4662, 1987.

Hedin, A. E., The atmospheric model in the region 90 to $2000 \mathrm{~km}$, in COSPAR International Reference Atmosphere: 1986, Part I: Thermospheric Models-CIRA-86, Adv. Space Res. 8, (5)9(5) 25,1988

Hedin, A. E., and G. R. Carignan, Morphology of thermospheric composition variations in the quiet polar thermosphere from Dynamic Explorer measurements, J. Geophys. Res., 90, 52695277, 1985.

Hedin, A. E., M. A. Biondi, R. G. Burnside, G. Hernandez, R. M. Johnson, T. L. Kileen, C. Mazaudier, J. W. Mewriwether, J. E. Salah, R. J. Sica, R. W. Smith, N. W. Spencer, V. B. Wickwar, and T. S. Virdi, Revised global model of thermospheric winds using satellite and ground-based observations, J. Geophys. Res., 96, 7657-7688, 1991

Ivanov-Kholodny, G. S., and A. V. Mikhailov, The prediction of ionospheric conditions, D. Reidel, Dordrecht, Holland, 1986.

Jones, G. O. L., K. J. Winser, and P. J. S. Williams, Measurements of plasma velocity at different heights along a magnetic field line, J. Atmos. Terr. Phys., 48, 887-892. 1986.
Kirchengast, G., R. Leitinger, and K. Schlegel, A high-resolution model for the ionospheric F-region at mid-and high-latitude sites, Ann. Geophysicae, 10, 577-596, 1992.

Kirkwood, S., P. N. Collis, and W. Schmidt, Calibration of electron densities for EISCAT UHF radar J. Atmos. Terr. Phys. 48, 773$775,1986$.

Lathuillere, C., and A. Brekke, Ion compositions in the auroral ionosphere as observed by EISCAT, Ann. Geophysicae, 3, 557$568,1985$.

Lathuillere, C., and B. Pibaret, A statistical model of ion composition in the auroral lower F-region, Adv. Space Res., 12, 147-156, 1992

Lathuillere, C., G. Lejeune, and W. Kofman, Direct measurements of ion composition with EISCAT in the high-latitude F1 region, Radio Sci., 18, 887-893, 1983.

McEwan, M. J., and L. F. Phillips, Chemistry of the atmosphere, Edward Arnold, London, 1975.

Mikhailov, A. V., and G. I. Ostrovski, Use of incoherent scatter data for determination of aeronomic quantities at F2 altitudes; annual variations of atomic oxygen. Geomag. Aeronom., 22, $44-48,1982$

Mikhailov, V. V., Yu. L. Teryokhin, and C. -U. Wagner, The evaluation of statistical accuracy for ionosphere F1-region theoretical model at low level of solar activity. Geomag. Aeronom., 29, 861-863, 1989.

Namgaladze, A. A., Ju. N. Korenkov, V. V. Klimenko, I. V. Karpov, F. S. Bessarab, V. A. Surotkin, T. A. Glushenko, and H. M. Haumova, A global numerical model of the Earth's thermosphere, ionosphere and protonosphere, Geomag. Aeronom., 30, 612-619, 1990.

Nusinov, A. A., Models for prediction of EUV- and X-ray solar radiation based on 10.7-cm radio emission. Proc. Workshop on Solar Electomagnetic Radiation Study for Solar Cycle 22, Boulder, Co., July 1992, Ed. R.F. Donnely, NOAA ERL. Boulder, Co., USA, 354-359, 1992.

Oliver, W. L., Incoherent scatter radar studies of the daytime middle thermosphere, Ann. Geophys., 35, 121-139, 1979.

Oliver, W. L., Improved Millstone Hill exospheric temperature measurements. Evidence for a seasonal variation of the magnetic activity effects, Geophys. Res., 85, 4237-4247, 1980.

Oliver, W. L., Neutral and ion composition changes in the $F$ region over Millstone Hill during the equinox transition study, $J$. Geophys. Res., 95, 4129-4134, 1990.

Oppenheimer, M., E. R. Constantinides, K. Kirby-Docken, G. A. Victor, A. Dalgarne, and J. H. Hoffman, Ion photochemistry of the thermosphere from Atmosphere Explorer C measurements, J. Geophys. Res., 82, 5485-5489, 1977.

Pesnell, W. D., Momentum transfer collision frequency of $\mathrm{O}^{+}-\mathrm{O}$, Geophys. Res. Lett., 20, 1343-1346, 1993.

Reddy, C. A., W. R. Hoegy, W. D. Pesnell, and C. O. Hines, Accuracy of $\mathrm{O}^{+}$- $\mathrm{O}$ collision cross-section deduced from ionosphere-thermosphere observations. Geophys. Res. Lett., 21 2429-2432. 1994.

Richards, P. G., D. G. Torr, B. W. Reinisch, R. R. Gamache, and P.J. Wilkinson. F2 peak electron density at Millstone Hill and Hobarth: Comparison of theory and measurements at solar maximum, J. Geophys. Res., 99, 15005-15016, 1994a.

Richards, P. G., D. G. Torr. M. J. Buonsanto, and D. Sipler. Ionospheric effects of the March 1990 magnetic storm: Comparison of theory and measurements, J. Geophys. Res., 99, 23359-23365, 1994b.

Roble, R. G., B. A. Emery, T. L. Killeen, G. C. Reid, S. Solomon, R. R. Garcia, D. S. Evans, P. B. Hays, G. R. Carignan, R. A. Heelis, W. B. Hanson, D. J. Winningham, N. W. Spencer, and L. H. Brace, Joule heating in the mesosphere and thermosphere during the July 13, 1982, solar proton event, J. Geophys. Res., 92, 6083-6090, 1987

Roble, R. G., E. C. Ridley, and A. D. Richmond, A coupled thermosphere/ionosphere general circulation model, Geophys. Res. Lett., 15, 1325-1328, 1988. 
Salah, J. E., J. V. Evans, and R. H. Wand, Seasonal variation in the thermosphere above Millstone Hill, Radio Sci., 9, 231-238, 1974.

Samarski, A. A., Introduction to the theory of difference equations, (in Russian) Nauka, Moscow, 1973.

Schunk, R. W., W. J. Raitt, and P. M. Banks, Effect of electric fields on the daytime high-latitude $\mathrm{E}$ and $\mathrm{F}$ regions. J. Geophys. Res., 80, 3121-3130, 1975.

Shibata, T., K. Inoue, and K. Schlegel, Ion composition in the lower $\mathrm{F}$ region inferred from residuals of ion temperature profile measured with the EISCAT CP1 experiments, $J$. Geomag. Geoelectr. 47, 879-888, 1995.

Sojka, J. J., Driving ionospheric models in real time, SolarTerrestrial Predictions-IV Workshop, Ottawa, Canada, May 1822, 393-400, 1993.
Torr, D. G., and M. R. Torr, Chemistry of thermosphere and ionosphere, J. Atmos. Terr. Phys., 41, 797-839, 1979.

Torr, M. R., D. G. Torr, and R. A. Ong, Ionization frequencies for major thermospheric constituents as a function of solar cycle 21, Geophys. Res. Lett., 6, 771-774, 1979.

Winser, K. J., A. D. Farmer, D. Rees, and A. Aruliah. Ionneutral dynamics in the high-latitude ionosphere: first results from the INDI experiment, J. Atmos. Terr. Phys., 50, 369377, 1988.

Winser, K. J., M. Lockwood, G. O. L. Jones, H. Rishbeth, and M. G. Ashford, Measuring ion temperatures and studying the ion energy balance in the high-latitude ionosphere. J. Atmos. Terr. Phys., 52, 501-517, 1990. 